\title{
Experiments on the Brown Rust of Bromes (Puccinia dispersa).
}

\author{
BY \\ E. M. FREEMAN, M.S., \\ University of Minnesota.
}

\begin{abstract}
$\mathrm{T}$
HE experiments from which the following results have been obtained were carried on in the botanical laboratory of Cambridge University, and I take pleasure in the acknowledgement of my indebtedness to Professor Marshall Ward for his many valuable suggestions and helpful direction, as well as for the excellent laboratory facilities afforded me. The experiments were undertaken for the purpose of obtaining, if possible, evidence on the brown rust of Bromes correlative to the recent work of Professor Ward ${ }^{1}$, viz. to test the infection capabilities of numerous species, among which were several whose systematic position in the genus has been somewhat doubtful, with spores from Bromus sterilis and $B$. mollis, using the reaction of plant and Fungus as an indication of the systematic affinities. The work was begun March I 9 and closed June 18 . The method of procedure was in general that used by Marshall Ward. Upon the first foliage leaf of seedlings of Brome plants, usually less than two inches high, were rubbed spores of the Uredo of $B$. sterilis and $B$. mollis respectively, a short distance from the apex of the leaf, or the spores were placed in the water-drop exuding from the water-stomata at the tip. The plants were then placed under moist bell-jars or beakers and kept in the laboratory for about twenty-four hours; they were then placed out

\footnotetext{
${ }^{1}$ Proc. Camb. Phil. Soc., vol. xi, pt. v; Proc. Roy. Soc. ; Annals of Botany, xv,
} No. lix, I90I.
\end{abstract}

[Annals of Botany, Vol. XVI. No. LXIII. September, 1902.] 
of doors, where the bell-jars were removed gradually to harden the plants to change of conditions. The spores used for infection were obtained from plants (both wild and cultivated) of $B$. sterilis and $B$. mollis from the University Botanical Gardens at Cambridge. Care was taken to prevent the admixture of leaves of other species. The cut-off leaves were placed in closed glass chambers for twelve to thirty-six hours before the spores were used. The determining condition of germination of the spores in distilled water are still enigmatical and have evidently narrow limits. Spores from the material used for each separate infection were tested in distilled water twenty-four to forty-eight hours. In most cases germination is abundant. Occasionally, however, apparently excellent spores may, under seemingly favourable conditions, almost utterly fail to germinate in distilled water, while spores from the same or neighbouring sori of the same leaf may successfully infect a Brome plant. Experiment $77 q^{\prime \prime \prime}$ is a very good example in point ${ }^{1}$, where no spores germinated in distilled water, while the infection of $B$. mollis with the same material was in each case (i.e. four out of four) successful. For this reason the negative results in the distilled water tests are not always an indication that the spores were incapable of germination. Dry spores were used in most cases, and in rubbing them on to the leaves of the host there arises the danger of dropping or shooting spores on to other parts of the plant or upon the control plants. Such may explain the infections of control plants in Experiments 94-96, in which cases an abundance of spores was used. Such infection may also be caused by the rubbing together of two leaves upon one of which spores have been placed (Marshall Ward, 1. c.). The plants after infection were examined at intervals of several days from about the eighth to twelfth day onward.

The weather throughout almost all of these experiments was colder than normal, and the long incubation period of most infections as compared with those noted by Marshall

1 These numbers refer to the tables of details of the experiments not published here in full. 
Ward is undoubtedly due to this cause. The rainfall though not excessive was evenly distributed, and sunshine less than normal throughout. The drying up of the infected leaves, though, in all probability, usually accelerated by the action of the Fungus, was in many cases due largely to severe weather conditions.

The results confirm in general those obtained by Marshall Ward, but under different seasonal conditions. The success of the infections under the unfavourable conditions encountered adds interest to the result, since it accentuates the possibility of natural field infections throughout the winter season. The following is merely an account of the experiments; the bearing of the results will, it is hoped, be more fully discussed in a future paper by Professor Marshall Ward.

The following tables sum up the results obtained during the progress of the experiments. The column ' host' includes the species upon which infections were made; then follow the species from which the brown rust spores were taken, viz. $B$. mollis and $B$. sterilis. About one half of the plants in each pot were infected and their position marked, so that the control and host plants could later be distinguished. This is of some importance, as in Experiment $94 q^{1}$, although five of ten plants were infected and five plants subsequently bore pustules, two of the pustules were on control plants and not due to the artificial infection unless accidental as indicated above. The germination of the spores in distilled water after twenty-four to forty-eight hours was classified as 'very poor' when only a few tubes can be found in the watch-glass; as 'excellent' when there are only a few spores which do not germinate. The intermediate conditions are self-explanatory. Records were kept of experiments in which all of the spore material was taken from the same leaf; and the numbers in the columns under the various dates indicate the number of plants whose infected leaves produced one or more pustules of brown rust.

The formation of yellow flecks in the leaves, which often 1 See footnote, p. 488. 
precede the sorus formation, is not always noted ; they may in some cases be due to other causes than the infecting Fungus. It happens very frequently that the tip of an infected leaf dries up. When this extends to or past the point of infection it is noted as 'tip-dried.' It is not a matter possible of exact determination how far the success of the infection is impaired in such cases. In many, pustules arise in the dried portions and in others below the point of infection. Those cases only are noted where it seems possible that the drying may have interfered with the growth of the Fungus. 'Leaf dried' denotes that the whole leaf has dried up. The unusually large number of dried leaves in Experiment 84 and 85 was due to very low temperature and a too sudden exposure of the plants to external conditions after infection.

When more than one leaf on a single plant shows pustules, it is in almost every case, without a doubt, due to a falling of spores from the infected leaf on to the leaf below; such are not included in the totals. Occasionally, pustules are reported and subsequently lost ; this may be due to one of two reasons. First, the infection material may, when in bulk, simulate a sorus, even under a lens, and the error may not be detected until a later examination; and second, the leaf may become dried, and if the pustule is small the latter may disappear.

Leaves 'missing' have been cut off by slugs or accidentally torn off in handling.

Each experiment was continued about three weeks; the incubation period of about twelve days prevents a second infection from the earliest pustules.

The following tables summarize the results. They include those plants with 'dried tips,' \&c., which were possibly incapable of forming pustules so that general averages only must be reckoned.

Series A gives twenty-two species. In I I, I2, and 19, and also in 15 and 16 , the number of plants worked with is too small for generalization. The same applies to several species included in the following series. In B. pitensis and B. unioloides large yellowish flecks were very easily produced but 
SERIES A. Unsuccessful with spores from both $B$. sterilis and $B$. mollis.

\begin{tabular}{|c|c|c|c|c|c|c|}
\hline \multirow[b]{2}{*}{ Host. } & \multicolumn{3}{|c|}{ Spores from B. sterilis. } & \multicolumn{3}{|c|}{ Spores from B. mollis. } \\
\hline & $\begin{array}{l}\text { Total No. } \\
\text { of Plants. }\end{array}$ & $\begin{array}{l}\text { No. in }- \\
\text { fected. }\end{array}$ & $\begin{array}{l}\text { No. success- } \\
\text { fully in- } \\
\text { fected. }\end{array}$ & $\begin{array}{l}\text { Total No. } \\
\text { of plants. }\end{array}$ & $\begin{array}{l}\text { No in- } \\
\text { fected. }\end{array}$ & $\begin{array}{l}\text { No. success } \\
\text { fully in- } \\
\text { fected. }\end{array}$ \\
\hline I. angustifolius & 6 & 5 & o & 5 & 4 & $\circ$ \\
\hline 2. arvensis & 29 & I 5 & o & 29 & 15 & 0 \\
\hline 3. asper & $6_{5}$ & 33 & $\circ$ & 69 & 35 & 0 \\
\hline 4. Biebersteinii & 20 & II & o & 23 & 12 & o \\
\hline 5. breviaristatus & 28 & I 4 & 0 & 40 & 20 & $\circ$ \\
\hline 6. carinatus & 54 & 27 & 0 & $5^{8}$ & 29 & o \\
\hline 7. ciliatus & 16 & 9 & $\circ$ & I 2 & 8 & $\circ$ \\
\hline 8. condensatus & I 4 & 8 & o & 8 & 4 & 0 \\
\hline 9. erectus & $5^{6}$ & 30 & $\circ$ & $7 \mathrm{I}$ & 37 & 0 \\
\hline Io. Hookerianus & IO & 5 & $\circ$ & ${ }_{15}$ & 8 & 0 \\
\hline I I. inermis & 3 & 3 & $\circ$ & 2 & 2 & 0 \\
\hline I2. Kalmii & I & I & $\circ$ & 7 & 4 & 0 \\
\hline I3. laxus & 29 & I 7 & 0 & 35 & I8 & o \\
\hline I4. parviflorus & Io & 5 & o & 20 & 10 & 0 \\
\hline I5. fibrosus & 8 & 4 & o & 6 & 4 & o \\
\hline 16. pitensis. & 9 & 6 & $\circ$ & I4 & 8 & o \\
\hline I7. pungens. & 23 & I 3 & 0 & 29 & I 6 & 0 \\
\hline 18. pumpelliamus & $5^{\mathrm{I}}$ & 26 & 0 & 59 & 30 & o \\
\hline 19. segetum & 2 & I & 0 & 6 & 3 & 0 \\
\hline 20. unioloides & 26 & I 4 & $\circ$ & 35 & I9 & 0 \\
\hline 2I. valdivianus & 29 & 17 & 0 & 24 & I3 & o \\
\hline 22. virens & 70 & 35 & 0 & 70 & 35 & o \\
\hline
\end{tabular}

Series B. Successfully infected with spores from $B$. mollis, but not with $B$. sterilis spores.

\begin{tabular}{|c|c|c|c|c|c|c|}
\hline 23. adoensis & 24 & $\mathrm{I}_{4}$ & o & I 7 & I0 & 9 \\
\hline 24. arduennensis & 6 & 4 & 0 & IO & 6 & 6 \\
\hline 25. commutatus & 24 & I3 & 0 & 28 & I 4 & 3 \\
\hline 26. grossus & $5^{8}$ & 30 & $\circ$ & 60 & 30 & I 5 \\
\hline 27. inermis (arvensis) & 36 & I9 & 0 & 36 & I9 & 3 \\
\hline 28. macrostachys & I 4 & 7 & 0 & I 4 & 7 & I \\
\hline 29. mollis & 106 & 53 & I? & 127 & 62 & 53 \\
\hline 3०. multiflorus & 5 & 3 & $\circ$ & II & 6 & 3 \\
\hline 3I. patulus & 27 & $I_{4}$ & 0 & I6 & 8 & 4 \\
\hline 32. squarrosus & 19 & I I & $\circ$ & 25 & I3 & I I \\
\hline $\begin{array}{l}\text { 33. squarrosus, var. } \\
\text { villosus }\end{array}$ & 25 & I 4 & $\circ$ & 23 & I 2 & 9 \\
\hline 34. arvensis (inermis) & 33 & 17 & $\circ$ & 20 & 10 & I \\
\hline
\end{tabular}

SERIES C. Successfully infected with spores from B. sterilis, unsuccessfully with B. mollis spores.

\begin{tabular}{|l|l|l|l|l|l|l|l|l|}
\hline 35. sterilis & 94 & $4^{8}$ & 44 & II5 & $5^{8}$ & 0 \\
\hline
\end{tabular}

SERIES D. Successfully infected with spores from both B. sterilis and B. mollis.

\begin{tabular}{|l|r|r|r||r|r|r|}
\hline 36. Gussoni & II 8 & 60 & 37 & 102 & 53 & 6 \\
37. Krausei & $5 \mathrm{I}$ & 29 & 14 & 53 & 27 & 27 \\
38. molliformis & 48 & 25 & I & 50 & 26 & 2 \\
39. Dendulinus & IOI & 53 & I & 98 & 50 & 30 \\
40. vestitus & 7 & 4 & I & 6 & 4 & 3 \\
\hline
\end{tabular}

1 Js probably same as 34 and both are probably incorrectly named (see next page). 
it is very doubtful if these were due to the infecting Fungus; no pustules were produced. The results with $B$. arvensis are at variance with those of Marshall Ward, who has found a successful infection of about 37 per cent. It is possible that at least some of the negative results of series $A$ are due to weather conditions.

Series B contains about eleven species. In $B$. adoensis, $B$. arduennensis, $B$. mollis, $B$. squarrosus, and $B$. squarrosus var. villosus, the percentage of successful infections is notably high. $B$. arduennensis, although the number of plants used is small, seems to be decisive in its results. $B$. grossus, $B$. multiflorus and $B$. patulus are also decisive but show more resistance to $B$. mollis spores, about 50 per cent. being successful. B. commutatus and 'B. inermis (arvensis),' which latter is probably identical with No. 34 , shows still less liability to infection. $B$. macrostachys requires more study, the single successful infection being insufficient for generalization.

Number 27 (and 34?) are Canadian forms and are probably $B$. arvensis, which, although my experiments give negative results, are according to those of Marshall Ward occasionally infected with $B$. mollis spores. In series D, B. Krausei, $B$. pendulinus and possibly $B$. vestitus, are more susceptible to mollis infection than to sterilis.

Series $C$ contains only $B$. sterilis. In the following series $B$. Gussoni has a much higher percentage of sterilis infections than of mollis.

Series D contains five species. B. Gussoni infects very readily (over 50 per cent.) with sterilis spores and over 10 per cent. with mollis. On the other hand, $B$. vestitus and $B$. pendulinus show greater susceptibility to mollis spore infection than to sterilis, but good percentages with both. In B. molliformis the percentages are too low and the differences insufficient for generalization, while $B$. Krausei infects with both species with remarkable ease. In the latter case infection with mollis spores is effected as easily if not more so than upon mollis itself, and the pustules are remarkable for size and vigour. With sterilis spores almost $5 \circ$ per cent. were successfully infected. 
It has been previously pointed out by Marshall Ward that the infection capacities of the brown rust spores are profoundly affected by conditions of formation and also by the host upon which they fall, and furthermore, that the optimum condition arises from infecting a species with spores formed on that species, which infection is least likely to succeed with spores of a species on those farthest removed in systematic position.

The results of series $A$ are negative and valuable only in connexion with further work on these species. In series B one would expect to find species with at least not very remote relationships with $B$. mollis.

Such species as B. commutatus, B. inermis (arvensis?), and macrostachys may have closer affinities with one of the other groups of Brome species than with the mollis group, but no close affinities with the $B$. sterilis. It will be seen by an examination of the members of the series that the expectations as to systematic position are in general realized. That intermediate forms between $B$. mollis and $B$. sterilis exist is an inference which may perhaps be drawn from series $\mathrm{D}$; i. e. at least $B$. Gussoni, $B . K$ rausei and $B$. pendulinus are quite susceptible to infection with spores from both species. $B$. Gussoni leans notably toward the sterilis side, while $B$. pendulinus and perhaps $B$. Krausei and $B$. vestitus would seem to be nearer to $B$. mollis. $B$. Krause $i$ is remarkable in the case of infection from both species, and there is probably some other factor to be considered besides the morphological and biological factors involved in the systematic position, because if $B$. Krause $i$ is an intermediate form, one would not find such extraordinary susceptibility to either species as is actually shown to exist toward mollis spores. If this additional factor is not all-important, and there is no reason to believe such to be the case, one would seek in the mollis group for the closer affinities of $B . K$ rausei.

The above results are all those of averages and there are several possible sources of error which must be borne in mind. The chief of these is to be found in the possibility of the admixture of stray spores from other species of Bromus than 
494 Freeman.-Experiments on Brown Rust of Bromes.

that experimented with; there is also the danger from foreign spores after the Brome seedlings expose their leaves to the air. Care in selection of spore material should reduce the former to a very small error. There is no control of the second condition, except in the selection of a place free from Bromes, if the plants are to be kept as nearly normal as possible, and this is essential. Since the pustules on an infected leaf in a great majority of cases arises in the immediate vicinity of the infection spot, there may be at least an indication when foreign contamination has taken place. Confusion is also possible with the uredos of other species of Puccinia growing on Bromes. Errors resulting in negative results, e. g. poor spore material or the presence of conditions which are unfavourable for germination and of which the limits and exact nature are as yet unknown, are less easy to detect, so that chief reliance is perhaps to be placed upon the positive results. 


\section{$2 \mathrm{BHL}$ Biodiversity Heritage Library}

Freeman, Edward Monroe. 1902. "Experiments on the brown rust of Bromes (Puccinia dispersa)." Annals of botany 16, 487-494.

https://doi.org/10.1093/oxfordjournals.aob.a088885.

View This Item Online: https://www.biodiversitylibrary.org/item/233980

DOI: https://doi.org/10.1093/oxfordjournals.aob.a088885

Permalink: https://www.biodiversitylibrary.org/partpdf/318686

\section{Holding Institution}

Smithsonian Libraries

\section{Sponsored by}

Biodiversity Heritage Library

\section{Copyright \& Reuse}

Copyright Status: Not in copyright. The BHL knows of no copyright restrictions on this item.

This document was created from content at the Biodiversity Heritage Library, the world's largest open access digital library for biodiversity literature and archives. Visit BHL at https://www.biodiversitylibrary.org. 